\title{
Systematic Chromosomal Analysis of Cultured Mouse Neural Stem Cell Lines
}

\author{
Giuseppe R. Diaferia, ${ }^{1}$ Luciano Conti, $2,{ }^{*}$ Serena Redaelli, ${ }^{3,{ }^{\star}}$ Monica Cattaneo, ${ }^{4}$ Cesare Mutti, ${ }^{2}$ \\ Pasquale DeBlasio, ${ }^{1}$ Leda Dalprà, ${ }^{3}$ Elena Cattaneo, ${ }^{2}$ and Ida Biunno ${ }^{4}$
}

The potential use of neural stem cells (NSCs) in basic research, drug testing, and for the development of therapeutic strategies is dependent on their large scale in vitro amplification which, however, introduces considerable risks of genetic instability and transformation. NSCs have been derived from different sources, but the occurrence of chromosomal instability has been monitored only to a limited extent in relationship to the source of derivation, growth procedure, long-term culture, and genetic manipulation. Here we have systematically investigated the effect of these parameters on the chromosomal stability of pure populations of mouse NSCs obtained after neuralization from embryonic stem cells (ESCs) or directly from fetal or adult mouse brain. We found that the procedure of NSCs establishment is not accompanied by genetic instability and chromosomal aberration. On the contrary, we observed that a composite karyotype appears in NSCs above extensive passaging. This phenomenon is more evident in ESC- and adult sub-ventricular zone-derived NSCs and further deteriorates after genetic engineering of the cells. Fetal-derived NSCs showed the greatest euploidy state with negligible clonal structural aberrations, but persistent clonal numerical abnormalities. It was previously published that long-term passaged ESC- and adult sub-ventricular zone-derived NSCs did not show any defects in the cells' proliferative and differentiative capacity nor induced in vivo tumour formation, although we here report on the chromosomal abnormalities of these cells. Although chromosomal aberrations are known to occur less frequently in human cells, studies performed on murine stem cells provide an important complement to understand the biological events occurring in human lines.

\section{Introduction}

$\mathrm{T}$ HERE ARE GREAT EXPECTATIONS from the employment of stem cells in biomedical practice. However, in addition to the large number of biological requisites cells must accomplish, their clinical exploitation should meet at least 2 requirements: (i) the occurrence of a normal genetic karyotype and (ii) the maintenance of chromosomal integrity during long term-culturing and after cryopreservation procedures. Careful and systematic cytogenetic analysis performed on several human embryonic stem cell (hESC) lines cultured in different laboratories has shown an overall preservation of euploidy during long-term culturing [1-4]. Nonetheless, recurrent amplification of $2.5-4.6 \mathrm{Mb}$ at $20 \mathrm{q} 11.21$ [5], gains of 2 chromosomal arms 12p, 17q [6], and occasional trisomy of chromosome 13 [7] have been reported. The highestresolution studies of hESCs performed so far have identified culture-induced copy number changes and loss of heterozy- gosity [8,9]. Many of the changes described affect DNA regulatory sequences $[10,11]$. Some of these alterations show close association with the extent of in vitro expansion and the conditions the cells are exposed to: media, $\mathrm{O}_{2}$ concentrations, and passaging conditions $[2,3,7,12]$. Notably, propensity to karyotype instability can vary between different lines, regardless of the culturing conditions, duration, or splitting techniques [13]. Although less investigated, in some cases also, mouse ESCs (mESCs) have been shown to accumulate chromosomal abnormalities during in vitro culturing and genetic engineering procedures [14-18], although such genetic changes did not affect the overall biological properties of the cells. When considering the adult stem cells, systematic cytogenetic analysis in relationship with the different preparation conditions, cell maintenance, and storage are scarce in scientific literature.

Mouse neural stem cells (NSCs) can be derived from different sources, and despite their wide use as model systems

\footnotetext{
${ }^{1}$ Department of Functional Biology, BioRep, Milan, Italy.

${ }^{2}$ Department of Pharmacological Sciences and Centre for Stem Cell Research, University of Milan, Milan, Italy.

${ }^{3}$ Department of Neurosciences and Biomedical Technologies, Università Milano-Bicocca, Monza, Italy.

${ }^{4}$ National Research Council-Institute for Biomedical Technologies, Segrate, Milan, Italy.

*These authors contributed equally to this work.
} 
for mammalian central nervous system development and differentiation, their karyotypic stability has been poorly characterized. The few available studies have enlightened the occurrence of genomic variability in NSCs suspension cultures (ie, "neurospheres")[19] with spontaneous transformation [20-23]. It has been recently reported that after 4 weeks in culture, fetal brain-derived neurospheres show reduced telomere length with subsequent gain of chromosome 1 and random structural chromosomal aberrations [24]. These changes have consequences on the proliferative behavior and functions of neurosphere cells [24-26], and it has been suggested that extensive in vitro culture might, in some studies, also generate malignant cells $[27,28]$.

Here we focused our attention on adherently growing, selfrenewing murine NSCs generated from ESCs and from primary fetal and adult central nervous system tissues [29-31]. These cells, named NSCs, resemble neurogenic radial glia of the developing brain $[32,33]$ and retain their multipotentiality while giving rise to up to $80 \%$ neurons after extensive in vitro expansion [29,30,33-36]. Further, these cells maintained their capacity to generate a high percentage of MAP2 neurons with a GABAergic phenotype and firing action potentials after more than 130 passages [35]. Moreover, ES- and fetal-derived NSCs never induced any tumor formation when implanted in mice [29] (Brilli et al. unpublished data). Although these cells did not show any biologically relevant alterations, the systematic cytogenetic analysis here reported on a number of NSC lines derived from different sources revealed variable degree of chromosomal aberrations. This phenomenon did not occur during the ESCs neuralization but is a function of the derivation source, passages, and genetic modifications. Extensive chromatin fibers occasionally appeared during the neuralization process, possibly as a consequence of cell stress. NSCs started to acquire the first abnormalities at passage 5, and these became more evident after genetic engineering. Moreover, NSCs derived from fetal mouse brain were comparatively more stable (but not exempted from abnormalities) with regard to sub-ventricular zone (SVZ)-derived and ESCderived NSCs. These results underscore the importance of performing routine cytogenetic analysis not only for studies dealing with lineage specification and maturation but also to test the potential effects of given chromosomal changes on the biochemical and physiological processes under investigation. A systematic analysis on murine stem cells is useful not only to regularly monitor their natural history but also to better understand stem cell biology.

\section{Materials and Methods}

\section{Maintenance of mouse stem cell lines}

NSCs have been derived and passaged as reported elsewhere [29,31]. Cells were routinely grown on uncoated $25 \mathrm{~cm}^{2}$ flasks (Iwaki, Barworld) in Euromed-N medium (Euroclone, Celbio) supplemented with 1\% N2 (Gibco, Invitrogen) and EGF and FGF-2 (20 ng/mL each; PeproTech, Tebu-Bio) [29]. Cells were regularly passaged by Accutase (Sigma) dissociation $\left(1-2 \mathrm{~min}\right.$ at $37^{\circ} \mathrm{C}$ ) and pelletted by centrifugation ( $3 \mathrm{~min}$ at $1.2 \mathrm{krpm}$ ). Medium was changed every 2-3 days.

L14 neurospheres were generated using a standard protocol [37] from E14 foetal striatum dissected from green fluorescent protein (GFP) reporter mice [38]. Neurospheres were grown in uncoated $25 \mathrm{~cm}^{2}$ flasks (Iwaki, Barworld) in the same medium used for NSCs expansion. Spheres were regularly pelletted by centrifugation ( $3 \mathrm{~min}$ at $1.2 \mathrm{k} \mathrm{rpm}$ ) and passaged 1:2 by mechanical dissociation every $4-5$ days.

Engineered LC-1 eGFP cells were obtained through infection of LC-1 cells (passage 12) by means of lentiviral particles carrying the eGFP cDNA [29]. Bulk culture of lentivirally infected LC-1 eGFP cells is indicated as LC-1 12+\# cells (\# indicates the passage after the engineering procedure). eGFP labelled COR-1 cells (COR-1 eGFP) were generated by electroporation procedure at passage 6 (cultures are indicated as COR-1 $6+\#$, where \# indicates the passage after the engineering procedure).

LC-2 subclones were generated by seeding LC-2 cells (passage 3 ) at the density of 0.5 cell/well in a laminin coated 96-well plate. Wells containing 1 single cell were selected under the microscope and followed for colony formation. Clones were expanded and passaged as just indicated.

Cells isolated from male mice were used for the experiments in order to maintain uniformity. A detailed description of the main properties of the cells used in this work is reported in Table 1.

Table 1. List of the Main Characteristics of the Neural Stem Cells Used for the Analysis

\begin{tabular}{|c|c|c|c|c|c|c|}
\hline Line & $\begin{array}{c}\text { Source } \\
\text { of derivation }\end{array}$ & Specie & $\begin{array}{l}\text { Type } \\
\text { of culture }\end{array}$ & $\begin{array}{c}\text { Genetic } \\
\text { manipulation }\end{array}$ & $\begin{array}{l}\text { Neurogenic } \\
\text { stability }\end{array}$ & Ref. \\
\hline ES46C & Embryo & Mouse & ESCs & NA & NA & {$[41]$} \\
\hline LC-1 \& LC-2 & ESCs & Mouse & NSCs & NA & Yes & {$[29,35]$} \\
\hline LC-1 eGFP & ESCs & Mouse & NSCs & $\begin{array}{l}\text { Lentiviral- } \\
\text { mediated } \\
\text { eGFP delivery }\end{array}$ & Yes & {$[29,35]$} \\
\hline aNS-1 & Adult SVZ & Mouse & NSCs & NA & Yes & {$[30,31]$} \\
\hline Cor-1 & Fetal cortex (E16.5) & Mouse & NSCs & NA & Yes & {$[29,36]$} \\
\hline Cor-1 eGFP & Fetal cortex (E16.5) & Mouse & NSCs & $\begin{array}{l}\text { Electroporation- } \\
\text { mediated } \\
\text { eGFP delivery }\end{array}$ & Yes & Unpublished \\
\hline L14 & Fetal Striatum (E14.5) & Mouse & Neurospheres & NA & Yes & Unpublished \\
\hline
\end{tabular}

All cell lines maintain neurogenic stability in culture evaluated by expression of immature, neuronal and glial antigents evaluated by immunocytochemistry in self-renewal or neuronal differentiation condition.

ESCs, embryonic stem cells; NSCs, neural stem cells; NA, not available. 


\section{Chromosome preparation and staining}

To obtain chromosome preparations, actively dividing cells from $70 \%$ to $80 \%$ confluent culture flasks were treated with $1 \mu \mathrm{g} / \mathrm{mL}$ Colcemid (Sigma) for $2 \mathrm{~h}$ at $37^{\circ} \mathrm{C}$. The cells were then collected by centrifugation at 2,000 rpm for $6 \mathrm{~min}$. A hypotonic solution consisting of $0.56 \% \mathrm{KCl} \mathrm{w} / \mathrm{v}$ prewarmed at $37^{\circ} \mathrm{C}$ was added to the cell pellet, prefixation with some drops of ice-cold fixative (methanol:glacial acetic acid, $3: 1, \mathrm{v} / \mathrm{v}$ ) was performed, and then cells were fixed with new cold fixative and stored at $+4^{\circ} \mathrm{C}$. About 3 drops of the cell suspension were dropped on cold, dry slides. Slides were stored at room temperature in a dry place and then stained for karyotype analysis.

\section{Quinacrine banding}

Q-bands by fluorescence and quinacrine stain (QFQ) banding was obtained by immersion of the prepared slides in a solution of quinacrine mustard $(5 \mathrm{mg} / \mathrm{mL}$; Sigma) for $1 \mathrm{~min}$ at room temperature, washed for $1 \mathrm{~min}$, and wetmounted in McIlvaine's Buffer under a coverslip. Metaphase chromosomes were analyzed with a Leica DMR fluorescent microscope, using a U.V. lamp, a $515 \mathrm{~nm}$ barrier filter, a H3 exciter filter (420-490 nm), and an immersion $100 \times$ objective.

\section{Giemsa banding}

GTG (G-banding by Trypsin and Giemsa) banding was obtained by trypsin digestion (1:250, Difco, 10\% in phosphate buffer) of the prepared slides for about $2 \mathrm{~min}$ at room temperature followed by Giemsa stain $(4 \%$ in phosphate buffer) for $12 \mathrm{~min}$. Metaphase chromosomes were observed with a Leica DMR microscope set in direct-light modality.

Images from the well-spread metaphases were captured using a CCD-camera with a dedicated software (Tesi Imaging, Italy).

The karyotypes were here described using the indication of the International Committee on Standardized Genetic Nomenclature for Mice [39,40], and the definitive karyotype is given by the analysis of about at least 50 metaphases per culture passage. A chromosomal aberration was defined as clonal when at least 2 metaphases showed the same aberration. If the abnormality was a missing chromosome, the same change had to be present in at least 3 cells to be accepted as clonal. Structural aberration was defined as rearrangement of chromosome segments resulting in the formation of ring chromosome, tandem or inverted duplication, and translocation.

\section{Results}

\section{Aneuploidy occurrence in cultured ESC-derived NSC lines}

NSCs derived from different sources have been shown to retain persistent self-renewal capacity and high neurogenic competence after extensive long-term in vitro culturing $[29,30,35,36]$. Previous studies showed that mouse NSCs maintain diploid chromosome content on at least 10 passages in vitro [29], but no indications were available on their stability after long-term expansion and genetic engineering.

In order to investigate these aspects, we first performed a karyotypic analysis on the already available LC-1 (mESC- derived) NSCs at passage 45 (p45) and LC-1 eGFP cells (carrying the eGFP transgene) at increasing passages (p12+10; $\mathrm{p} 12+18$ and $\mathrm{p} 12+40)$. We found that the percentage of euploidy in p45 LC-1 cells was very low, bringing clonal numeric and structural aberrations to $58 \%$ and $2 \%$, respectively (Table 2 and Fig. 1a). Only one metaphase showed a Robertsonian translocation involving chromosome 5 and 16 $(\mathrm{Rb}(5.16))$. These abnormalities were also further evident in the LC-1 eGFP cells, in particular at passages $12+18$ and $12+40$, which were completely devoid of metaphases with normal complement (Table 2 and Fig. 1a). An additional marked characteristic of LC-1 and LC-1 eGFP cells was their tendency to tetraploidy $(2 \mathrm{n} \geq 80)$. In particular, this was true at p12+10 (about 6\%) and p12+40 (about 90\%) for LC-1 eGFP, whereas in parental LC-1 cells, just few metaphases showed a tetraploid complement. At the different passages considered, metaphase reconstruction of LC-1 eGFP also showed, at each passage considered, a composite karyotype with different chromosomes involved generally in clonal aneuploidies that were all shared simultaneously by different metaphases. Random chromosomal loss was evident, mainly in p12+18 metaphases $(33.4 \%)$. The presence of small fragments of extrachromosomal DNA was also recorded in LC-1 eGFP cells with a frequency increasing, during in vitro expansion, from $13.3 \%$ to $46.7 \%$ (Table 2 ), likely due to cell stress. These fragments are referred to as marker chromosome (mar) even if they showed different morphologies such as ring-shaped chromosome fragments with centromere and acentric fragments (Fig. 2).

On the whole, these results indicate that ES-derived NSCs lose their euploidy with long-term passaging and genetic engineering.

\section{Analysis of the effects of neuralization process and passages on the karyotype of ES-derived NSCs}

In order to systematically investigate the onset and progression of karyotipic abnormalities observed in long-term expanded and engineered LC-1 cells, we derived a new NSC line (named LC-2 cells) from mESCs. Analysis was performed on the starting ESC culture, the intermediate transient neural progenitors (NPs) [33], and the stabilized LC-2 cells at different in vitro passages before and after cryopreservation. In order to keep consistency with the previous LC-1 derivation, we employed the same ES46C mESC line [29]. Analysis of the starting ESC culture did not reveal abnormalities (Table 3), reinforcing the evidence of a broad genetic stability and integrity of the starting mESC culture. According to the NSC generation procedure [29], ES46C cells exposed for 7 days to N2B27 medium enter the neuralization phase and efficiently convert into a population of sox-1 positive NPs [41]. These represent a transient intermediate population that is transferred to EGF and FGF-2 supplemented serum-free medium (SFM) which ultimately convert them into stable, homogeneous, and long-term self-renewing NSCs [29,33]. Table 3 shows that NPs exhibited a normal chromosomal pattern with no manifest structural or numeric aberration, but a consistent fraction (about 50\%) of NPs in culture exhibited the presence of extra-chromosomal chromatin fibers (Fig. 3). These structures consist of thin DNA threads that connect chromosomes [42] and resemble chromonemal fibers [43]. These fibers appear early in the NP generation phase and gradually dis- 


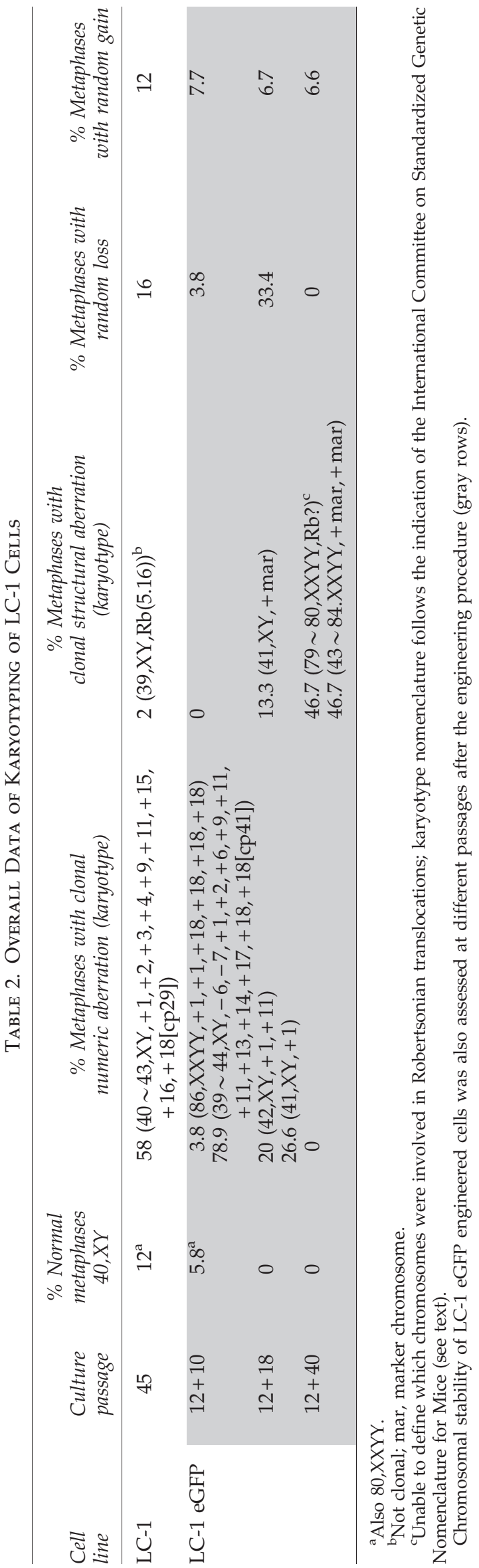

appear after complete NS conversion and subsequent in vitro culturing. We speculate that these fibers might be the result of a change of chromatinic status occurring during the transition from pluripotent ESCs to a somatic stem cell population or of a gradual adaptation of the cells to serum-free conditions they were exposed to during the neuralization process. When freshly generated LC-2 NSCs at p1 were analyzed, a stable chromosomal asset was found (Table 3). Nevertheless, passaging led to the appearance of minor structural (Rb19:19 at p3) and numeric aberrations (monosomy of chromosome 2 and 13 and trisomy of chromosome 1 and 12 at p5) although most of them were not clonal (Table 3$)$. With in vitro passaging, LC-2 cells progressively showed signs of chromosomal instability, gaining clonal numeric aberrations of chromosomes 1 and/or 19 in about $50 \%$ of the metaphase analyzed (Table 3 and Fig. 1a), whereas no significative variation in random gain/loss was observed.

\section{Karyotipic analysis of clonal populations of NSCs}

In order to investigate the karyotipic stability of clonal populations, we analyzed the chromosomal pattern of different subclones generated from LC-2 (p3) bulk culture. We considered 5 different clones analyzed at p3 and p15 (Table 4). Among the 5 clones considered, 2 (LC-2_8 and LC-2_13) showed low instability and sporadic gain of chromosomes 11 and 19 and loss of 3,13, and 14. Structural aberrations (presence of supernumerary chromosome "mar" and Robertsonian translocations) were observed only in single metaphases and they were lost with passages (Table 4). Although these events were casual and likely due to technical preparation of metaphase spreads, those occurring in LC-2_15, LC-2_20, and LC2_22 were clonal being present in more than 3 metaphases. These cells acquired structural aberrations involving chromosomes 16 and 19 and gain of chromosomes 1, 5, and Y. These results indicate a certain heterogeneous intrinsic instability of this cell type and the tendency to acquire several aberrations that can be selectively clonally propagated in culture.

\section{Analysis of the effects of cryopreservation procedure on the karyotype of ES-derived NSCs}

In order to evaluate the effect of cryopreservation on possible occurrence of kariotypic instability, LC-2 cells were frozen at p5 in regular freezing medium containing 10\% dimethyl sulfoxide, thawed, and cultured for another 7 and 30 passages (p5+7 and p5+30). The frozen/thawed LC-2 cells showed extra-chromosomal chromatin fibers in $12 \%$ of metaphases that were lost after 30 passages post-thawing; at this time point, the cells displayed clonal trisomy of chromosome 1 and 19 (Table 3, gray rows) as for the same cells continuously cultured without cryopreservation (Table 3, passage 40). These data indicate that when clonal aneuploidy occurs, the same chromosomes are maintained in the cells independently of the cryopreservation steps.

\section{NSCs derived from the adult and fetal brain show different susceptibility to accumulate chromosomal aberrations with long-term in vitro culturing}

We next analyzed the chromosomal organization of NSCs previously derived from the fetal and adult mouse brain [29-31]. In particular, adult SVZ-derived aNS-1 cells were 

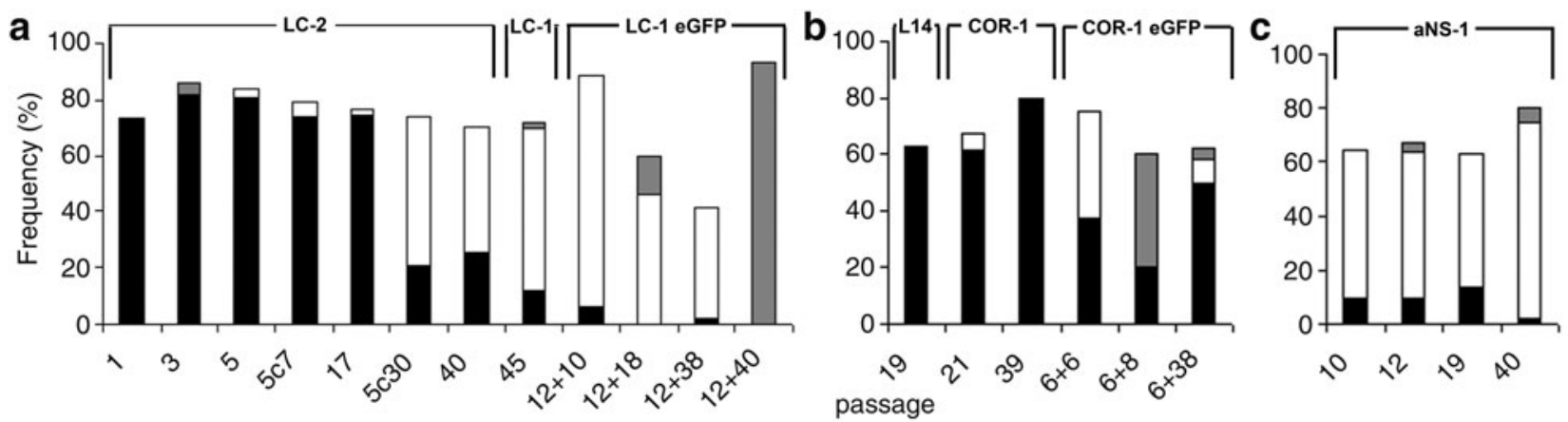

- Normal

$\square$ Clonal Numeric Aberrations $\square$ Clonal Structural Aberrations

FIG. 1. The frequency of euploidy, number of clonal/structural aberrations, and random loss/gain during the period of culture passage in: (a) mouse embryonic stem cell-derived neural stem cells (LC-1 and LC-2) and engineered subclone (LC-1 eGFP); (b) mouse fetal (E15.5) cortex cells (COR-1), engineered subclone (COR-1 eGFP), and mouse neurospheres from fetal (E14.5) striatum (L14); (c) adult mouse neural stem cell derived from subventricular zone (aNS-1). +\# indicates the passages after the engineering procedure and c\# indicates the passages after the cryopreservation.

cytogenetically examined at different passages (p10, p19, and $\mathrm{p} 40$ ), and euploid frequencies are reported in Table 5. A greater frequency of clonal aneuploidies than structural aberrations occurred in these cells (Table 5 and Fig. 1c), trisomy of chromosome 1 being the most frequent numeric aberration ranging from $29 \%$ (passage 10 ) to $62 \%$ (passage 40 ). Much less frequent were trisomies of chromosomes 18 and 19, whereas at p10 the presence of a supernumerary chromosome 19 was recorded as showing duplication of the $q$ arm in C band (Dp(19C); Fig. 4a).

COR-1 (fetal brain derived) NSCs were cytogenetically analyzed at passages 21 and 39. Although we observed euploidy in about $61.2 \%$ and $80 \%$ of cells at passages 21 and 39, respectively (Table 5 and Fig. 1b), there were no evident clonal structural aberrations, but only a low percentage of clonal monosomy of chromosome 17 (6.1\% at passage 21$)$. This alteration is lost with further passaging, and the random gain/loss observed in both passages was likely due to metaphase preparation.

On the whole, these results indicate that NSCs derived from fetal brain also carry chromosomal abnormalities but are less subjected to accumulate karyotipic aberrations than adult SVZ-derived NSC lines.

\section{Monolayer of NSCs versus suspension neurosphere growth of fetal brain cells}

In order to assess whether monolayer NSC culturing procedures can differently impact on chromosomal instability with regard to the suspension neurosphere culturing, we analyzed L14 neurospheres at passage 19. L14 were derived according to standardized procedures from the E14 mouse fetal brain [19]. Of the 54 metaphases analyzed in this cell line, $63 \%$ showed normal karyotype with no clonal aneuploidy (Table 5 and Fig. 1b). Random chromosome loss and gain was $24 \%$ and $13 \%$, respectively, but this might be associated with technical artefacts (Table 5). Only 3 metaphases showed a complex karyotype: (i) 40,XY,-8, +Dp(19C) showing loss of chromosome 8 and a supernumerary chromosome 19 with a duplication of $\mathrm{q}$ arm in $\mathrm{C}$ band; (ii) $39, \mathrm{XXY},-9, \mathrm{Rb}(3.5)$ resulting from a Robertsonian translocation between chromosome 3 and 5 (Fig. 5a); this metaphase also showed a duplication of the $X$ chromosome and loss of chromosome 9; (iii) 40,XY, $\mathrm{Rb}(4.4)$ in which chromosome 4 was present in 3 copies consisting of normal 4 and a Robertsonian translocation between two chromosomes 4 linked together at the centromere (Fig. 5b).
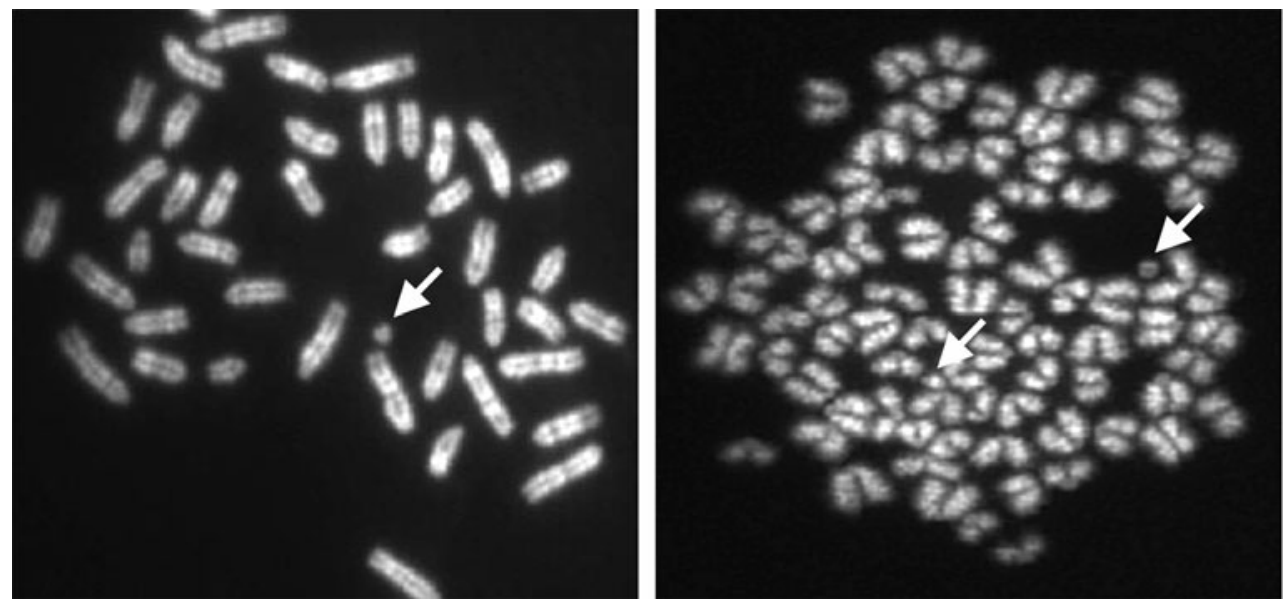

FIG. 2. Line LC-1 eGFP: examples of different mars (marker chromosomes; arrows) in a diploid (left) and tetraploid (right) metaphase. 


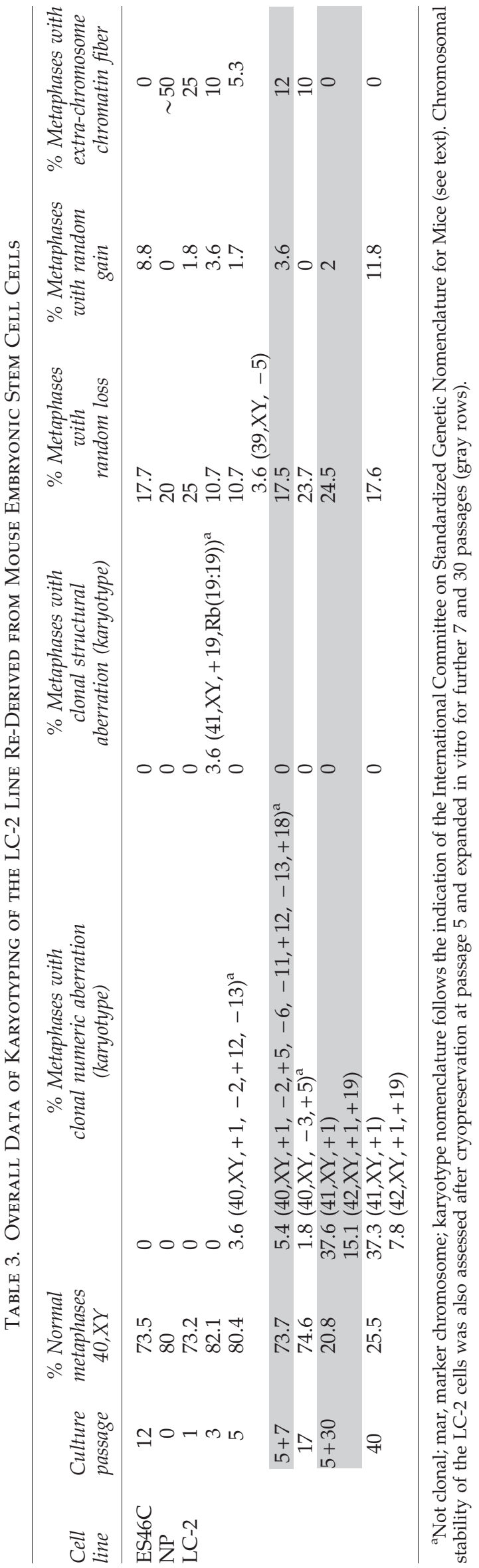

On the whole, these results indicate that neurosphere cultures are comparable to monolayer of fetal NSCs in term of chromosomal instability.

\section{The effect of genetic engineering on fetal-derived NSCs}

Finally, aiming at assessing whether genetic engineering might worsen the chromosomal pattern of fetal-derived NSCs, as previously observed for ESC-derived NSCs (Table 2), we analyzed cultures of engineered COR-1 eGFP at p $6+6$ and p6+38 (Table 5, gray rows). Although the mitotic index for these cells was low (few metaphases per passage) except for passage $\mathrm{p} 6+38$, euploidy ranged from $50 \%$ at p $6+38$ to $37.5 \%$ at $\mathrm{p} 6+6$, suggesting that only cells with a normal complement succeed in completing cell division and are positively selected. In these cells, clonal aberrations both numeric and structural were reported (Table 5 and Fig. 1b). Notably, we observed deletion of chromosome 1 from $\mathrm{C}$ band of $\mathrm{q}$ arm to Tel1 $\mathrm{q}$ $(\operatorname{del}(1 \mathrm{C}))$ with a frequency of $4 \%$ in p6+38 (Fig. 4b). Clonal monosomy for chromosomes 13 and 19 were observed at passage $6+6$ with a frequency of $37.5 \%$ and of $8 \%$ at passage $6+38$, respectively (Table 5).

These results indicate that engineering procedures applied to the established mouse NS lines exacerbate the accumulation of the chromosomal defects independently of the source of origin of the NSCs.

\section{Discussion}

Several evidences have described the onset of chromosomal abnormalities in cells grown in vitro $[20,44,45]$. This has also been reported to occur occasionally during mESC derivation and culturing [46]. Similar abnormalities have been found in neurons and glia in the normal brain, likely due to mitotic segregation defects occurring in neural progenitor cells [47]. In particular, a number of studies now indicate that within the adult human and mouse SVZ and other brain regions, there are a considerable number of neural stem/progenitor cells showing loss of heterozygosity and an abnormal karyotype resulting in chromosomal mosaicism and cellular diversity [48]. Structural variation in the neural genome is likely to be one important mechanism for neuronal diversity, as functioning neurons with aneuploid genomes form genetically mosaic neural circuitries as part of the normal organization of the mammalian brain [49]. Accordingly, these chromosomal changes may be brought in vitro $[20,47,50]$. The presence of chromosomal abnormalities in cultured neural stem/progenitor cells may, thus, reflect the brain area from which the cells originate $[21,51]$ in addition to the way in which NSCs are isolated or processed, their long-term cultivation [52] and, possibly, cryopreservation conditions.

Here we performed a systematic cytogenetic analysis of mouse adult, fetal, and ES-derived NSC lines at different culturing passages summarized in Fig. 1 and Table 6. We found various chromosomal abnormalities including polyploidy, mono and trisomy, translocations and duplications in all the cell lines considered. As previously reported, chromosomes gain (either total or partial acquisition) predominate over loss in all cell lines analyzed as a function of culturing passages [15]. In general, cells in culture acquire 

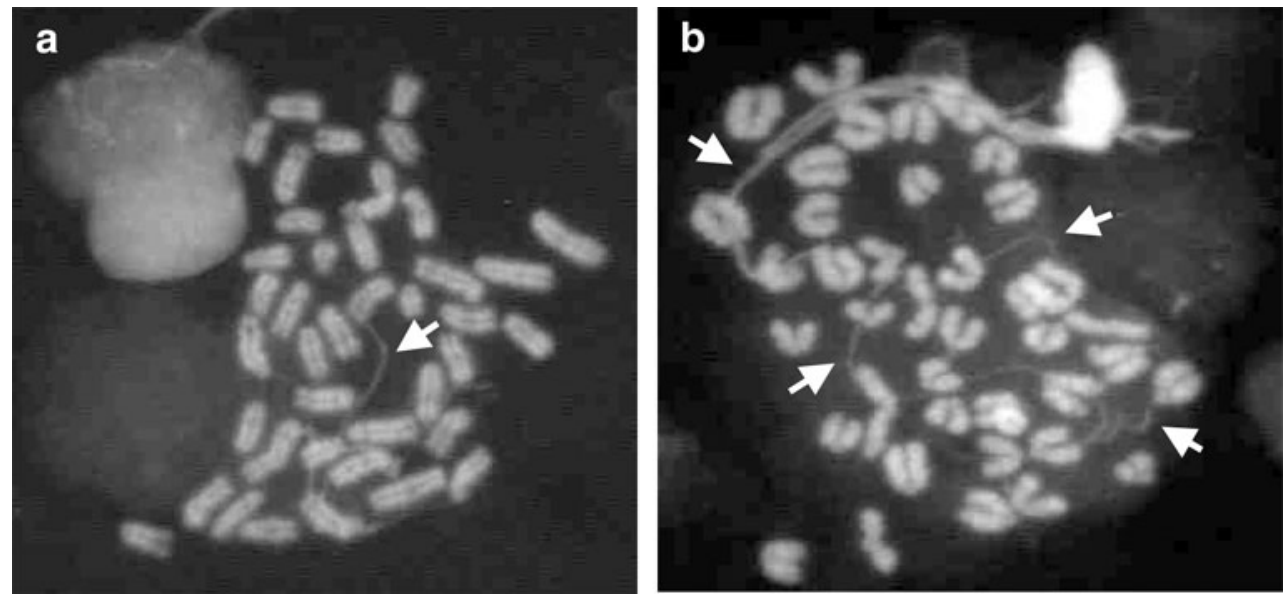

FIG. 3. Examples of extrachromosomal chromatin fibers (arrows) in neural progenitor (NP) cells $(\mathbf{a}, \mathbf{b})$.

DNA damage and likely undergo random mutations at a rate of about 1 nucleotide per $10^{9}$ cells [2]. These phenomena may confer gradual adaptation to the in vitro synthetic environment. Besides the numerous and diverse nature of the alterations, we have observed the presence of chromatin fibers in a number of metaphases that represent unfolding of entire or partial chromosomes. Extensive chromatin fiber conformation influences DNA tension [53], linker histone H1 binding to NAP1 [54], and in vivo and in vitro DNA methylation-dependent chromatin fiber compaction [55]. It has been observed that during the development of transient organs in animals and plants, sister chromatids usually do not become separated after replication rounds and retain cohesion at highly reiterated sites as centromeres. This might trigger the formation of hyperploid cells, a condition widely observed in stem cell lines and malignant tumors that arises initially from cells arrested in the G2/M or spindle checkpoint, unable to segregate chromosomes by mitosis [56]. We mainly detected the presence of these fibers in some cells during the neuralization phase, when cultures are exposed to serum-free media and, therefore, subjected to considerable stress adaptation. Their presence gradually decreased as cells proceeded toward the NSC stage differentiation, whereas numerical and structural chromosomal aberrations increased with the number of passages. Serum starvation may represent a source of chromosomal instability, as it can induce structural aberrations and aneuploidy [57]. It has been reported that human fetal fibroblasts exposed to serum deprivation display double centrosomeres, translocation, deletions, and high telomerase activity, which, in turn, might cause cellular transformation. It may be that the decondensation of the chromatin, either totally or partially, may set the stage for further chromosomal breakage and dysfunctions. Further studies are required in order to elucidate the exact biological role of these structures in cultured cells.

However, ESCs subjected to serum starvation for 7 days during neuralization procedure did not show any chromosomal aberration, which were instead appearing only after NSC lines were established. The most affected were the ESC derived LC-1 and LC-1 eGFP cells, the latter showing tetraploidy $(2 n>80)$ in about $90 \%$ of the metaphases (passage12+40). LC-1 eGFP cells (derived from LC-1 cell line on lentiviral infection carrying the cDNA for the GFP protein) exhibited further severe clonal numeric and structural aber- rations with regard to the parental LC-1 cells. Insertion of foreign genetic material via retroviral vectors is known to trigger genomic instability, especially when the number and sites of insertion are arbitrary [58-60]. Nevertheless, this technique is normally used to trace cells after transplantation to follow migration/integration in the host tissue and lineage specifications [61].

In the literature, there are divergent data on chromosomal stability of non-immortalized NSC lines and some data indicate that, at least for adult mouse SVZ-derived NSCs, chromosomal abnormalities are actually expected. Morshead and colleagues [27] reported that neurospheres after 15-20 passages undergo transformation as indicated by decreased doubling time, loss of growth factor dependence, or differentiative potential. Similar observations have been recently reported for mouse fetal-derived neurospheres [24]. On the contrary, one other study [62] reported that non-clonal neurosphere cultures derived from mouse adult (2 month old) SVZ are karyotypically normal until passage 40 (when they generate $\sim 15 \%$ of $\beta 3$-tubulin immunoreactive cells) but later at passage 70 begin to exhibit chromosomal aberrations in $10 \%$ of cells although no variation(s) on the behavior was reported. In our hands, fetal-derived neurosphere culture did not show any clonal aberrations at passage 19 although sporadic alteration of chromosomes 3,5, and 19 were found as also described by other authors [24]. Also, no significant differences were reported when fetal NSCs were cultured in adherence, suggesting that none of these culture methods protects NSCs from gaining clonal aberrations.

We conclude that NSCs from different sources can manifest a variable tendency to acquire karyotypic aberrations, especially after extensive in vitro expansion. Fetal NSCs seem to acquire less chromosomal anomalies in culture. This might be due to programmed cell death that naturally occurs in vivo in more than $20 \%$ of fetal brain cells coincidental with early developmental processes of proliferation, migration, and differentiation [63]. The clearance of aneuploid cells in the developing brain could be one of the main functions of programmed cell death [48]. On the contrary, recent studies have hypothesized that mitotic-spindle checkpoint, which helps maintain chromosomal integrity during cell division, functions in hESCs and mESCs but does not initiate apoptosis as it does in somatic cells [64]. This allows an unusual tolerance to polyploidy resulting from failed mitosis. Thus, 


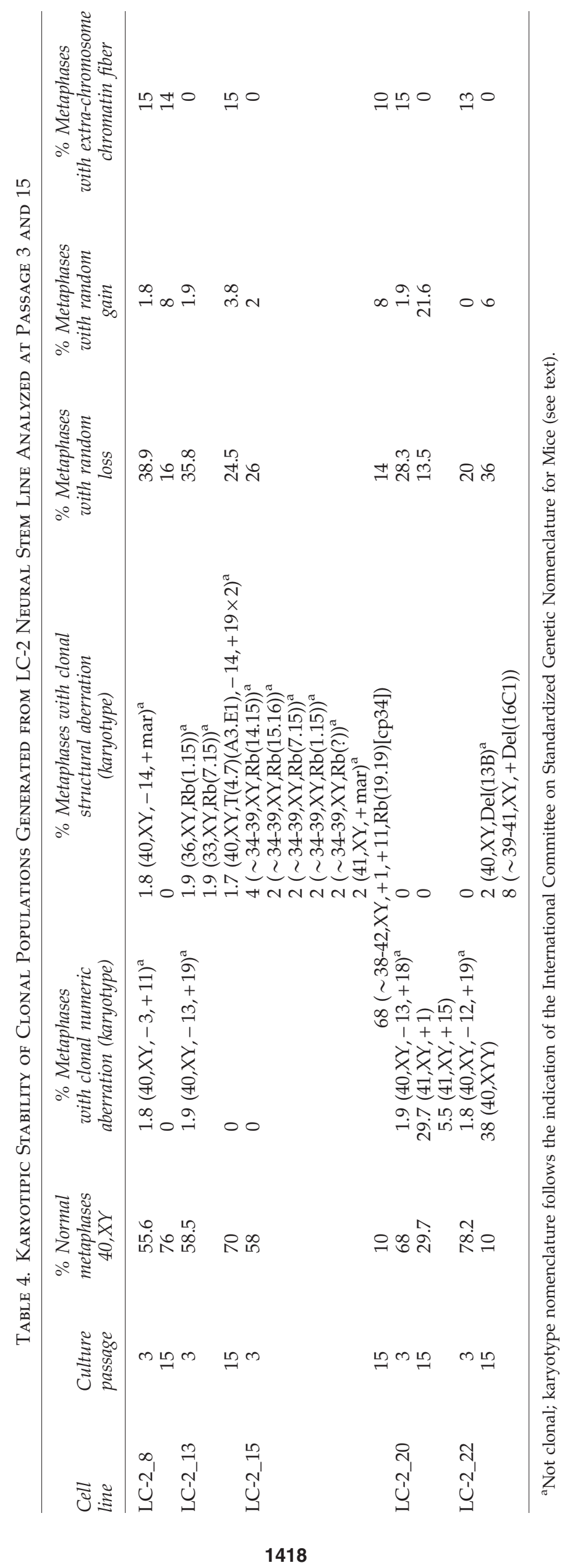




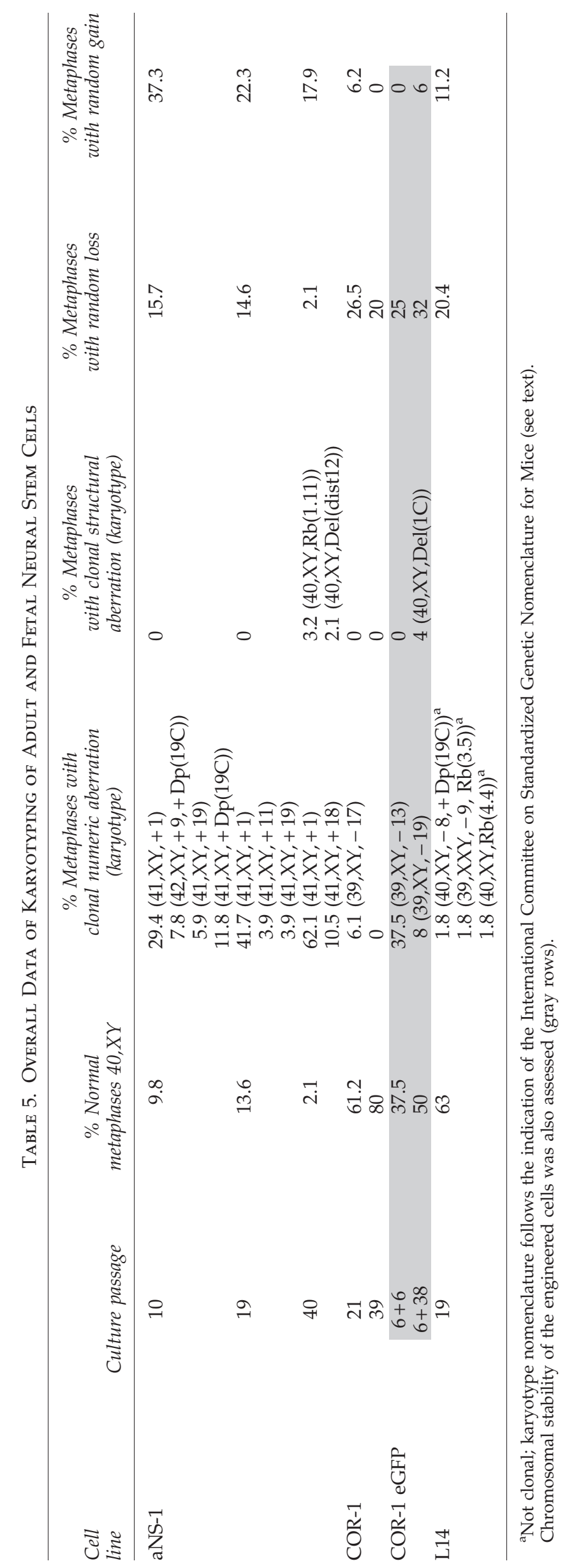


FIG. 4. (a) Line aNS: the arrowheads indicate the chromosome 19; the arrow indicates $\mathrm{Dp}(19 \mathrm{C})$. In the box representation of $\mathrm{Dp}(19 \mathrm{C})$ in comparison with chromosome ideogram and normal chromosome 19. (b) Line COR-1 eGFP: the arrowhead indicates the chromosome 1; the arrow indicates $\operatorname{Del}(1 \mathrm{C})$. In the box representation of $\operatorname{Del}(1 \mathrm{C})$ in comparison with chromosome ideogram and normal chromosome 1.
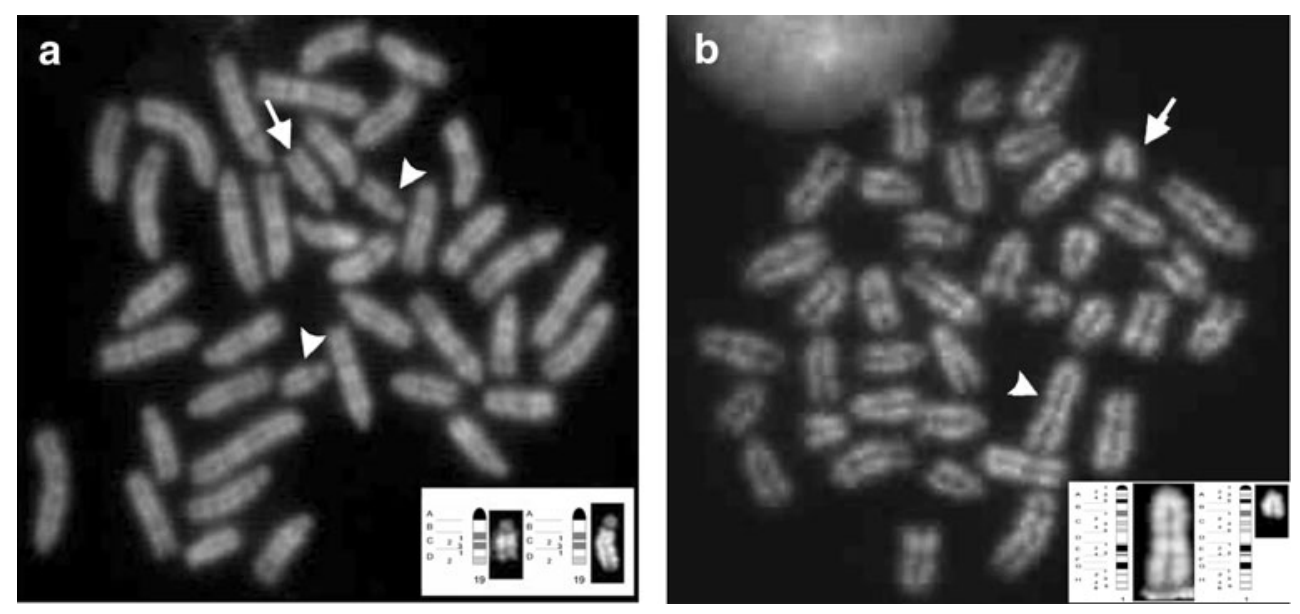

FIG. 5. Line L14: examples of Robertsonian translocations. (a) $\mathrm{Rb}(3.5)$ (arrow) and (b) $\mathrm{Rb}(4.4)$ (arrow). In the boxes, particulars of the derivative chromosome and normal chromosomes are shown.
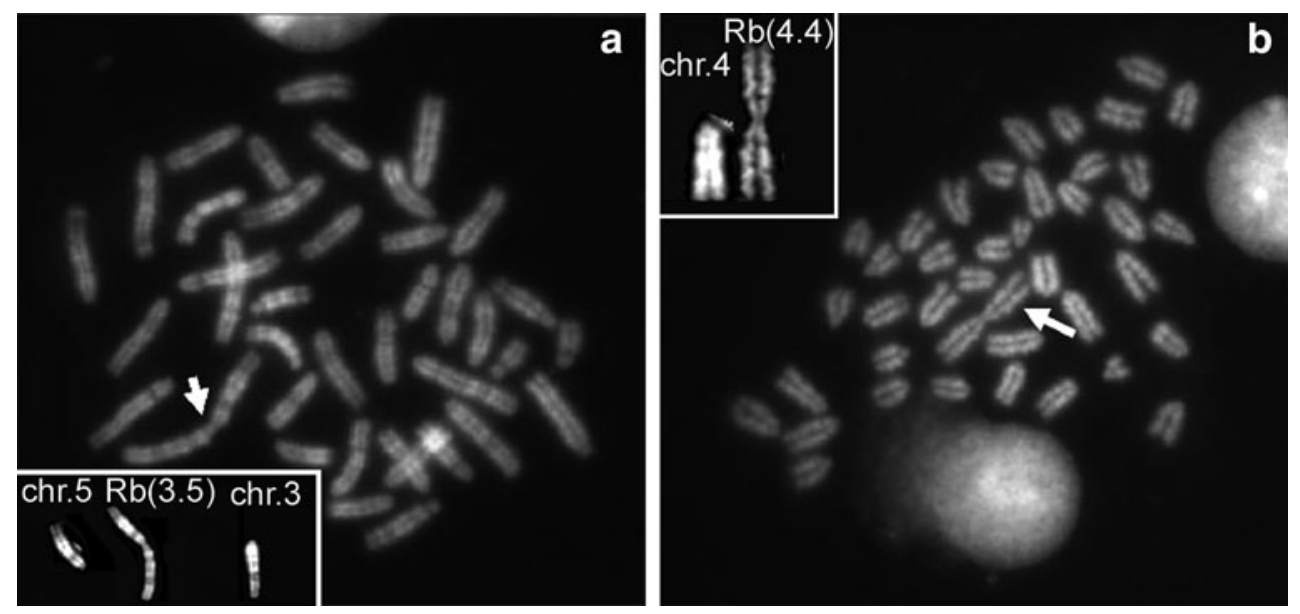

the spindle checkpoint is "uncoupled" from apoptosis in stem cells and is a likely source of karyotypic abnormalities. Importantly, in spite of the chromosomal anomalies observed in ES-, fetal- and adult-derived NSCs, we never observed important modifications in the biological behaviour of NSCs, also after prolonged growth in culture, that might be indicators of cellular transformation [29,30,35]. Aneuploidy and chromosomal aberrations also frequently occur in cultured cells in the absence of any predisposition to transformation $[49,62]$. Similarly, the chromosomal abnormalities observed in the cell lines herein tested did not lead to any alteration in their differentiation capacities as previously demonstrated $[30,35,36]$, and none of the NSC lines tested in this manuscript has ever led to tumor formation when implanted in mice, even after more than 70 in vitro passages [29] (Brilli et al., unpublished data).

Table 6. Hit Map of the Most Affected Chromosomes in the Neural Stem Cell Lines Analyzed

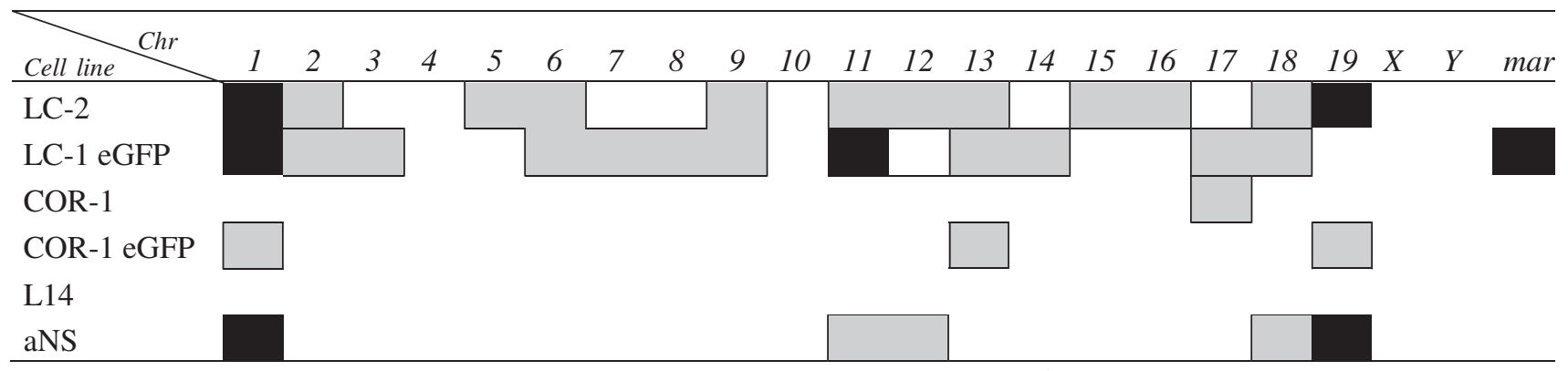

In black, the clonal chromosomal aberrations (either numeric or structural) mantained in further passages; in gray, clonal chromosomal aberrations observed only at a specific passage. 


\section{Conclusions}

Given the huge potential of NSCs as model systems to study molecular events in normal and pathological processes, it is important to monitor genomic changes in cultured cells and to eventually determine the impact of such changes. Rapid loss of euploidy and accumulation of chromosome aberrations as a function of passage are probably inherent to most of the in vitro expansion procedures, at least for mouse cells, and may be even part of a physiological process in vivo.

Our results indicate that chromosomal aberrations accumulate in NSCs with passages in vitro in conjunction with loss of euploidy. It is still unclear what triggers the numerous and diverse chromosome abnormalities observed in NSCs, especially the ones derived from ESCs and adult SVZ. This may be related to the culturing conditions, the methods of dissociation, and the percentage of $\mathrm{O}_{2}$.

Our results suggest that mouse NSCs in culture have a predisposition to genetic instability although they do not apparently exhibit visible variations in their growth and differentiation properties. These results also open to the need to define new culture conditions to decrease chromosomal alterations in long-term cultures and should encourage researchers to perform regular high-resolution molecular and cytogenetic studies to monitor the chromosome integrity of in vitro expanded stem cell cultures.

\section{Acknowledgments}

Research activities are supported by NEUROscreen consortium (European Community's Sixth Framework Programme grant agreement LSHB-CT-2007-037766) to P.D. and L.C. and by NeuroStemcell (European Community's Seventh Framework Programme grant agreement nr. HEALTH-2008B-222943) to I.B. and E.C.

\section{Author Disclosure Statement}

No competing financial interests exist.

\section{References}

1. Hoffman LM and MK Carpenter. (2005). Human embryonic stem cell stability. Stem Cell Rev 1:139-144 Review.

2. Maitra A, DE Arking, N Shivapurkar, M Ikeda, V Stastny, K Kassauei, G Sui, DJ Cutler, Y Liu, SN Brimble, K Noaksson, J Hyllner, TC Schulz, X Zeng, WJ Freed, J Crook, S Abraham, A Colman, P Sartipy, S Matsui, M Carpenter, AF Gazdar, M Rao and A Chakravarti. (2005). Genomic alterations in cultured human embryonic stem cells. Nat Genet 37:1099-1103.

3. Mitalipova MM, RR Rao, DM Hoyer, JA Johnson, LF Meisner, KL Jones, S Dalton and SL Stice. (2005). Preserving the genetic integrity of human embryonic stem cells. Nat Biotechnol 23:19-20.

4. MA Prokhorovich, MA Lagar'kova, AG Shilov, TV Karamysheva, SL Kiselyov and NB Rubtsov. (2007). Cultures of hESM human embryonic stem cells: chromosomal aberrations and karyotype stability. Bull Exp Biol Med 144:126129.

5. Lefort N, M Feyeux, C Bas, O Féraud, A Bennaceur-Griscelli, G Tachdjian, M Peschanski and AL Perrier. (2008). Human embryonic stem cells reveal recurrent genomic instability at 20q11.21. Nat Biotechnol 26:1364-1366.
6. Draper JS, K Smith, P Gokhale, HD Moore, E Maltby, J Johnson, L Meisner, TP Zwaka, JA Thomson and PW Andrews. (2004). Recurrent gain of chromosomes 17q and 12 in cultured human embryonic stem cells. Nat Biotechnol 22:381-382.

7. Caisander G, H Park, K Frej, J Lindqvist, C Bergh, K Lundin and C Hanson. (2006). Chromosomal integrity maintained in five human embryonic stem cell lines after prolonged in vitro culture. Chromosome Res 14:131-137.

8. Närvä E, R Autio, N Rahkonen, L Kong, N Harrison, D Kitsberg, L Borghese, J Itskovitz-Eldor, O Rasool, P Dvorak, O Hovatta, T Otonkoski, T Tuuri, W Cui, O Brüstle, D Baker, E Maltby, HD Moore, N Benvenisty, PW Andrews, O Yli-Harja and R Lahesmaa. (2010). High-resolution DNA analysis of human embryonic stem cell lines reveals cultureinduced copy number changes and loss of heterozygosity. Nat Biotechnol 28:371-377.

9. Wu H, KJ Kim, K Mehta, S Paxia, A Sundstrom, T Anantharaman, AI Kuraishy, T Doan, J Ghosh, AD Pyle, A Clark, W Lowry, G Fan, T Baxter, B Mishra, Y Sun and MA Teitell. (2008). Copy number variant analysis of human embryonic stem cells. Stem Cells 26:1484-1489.

10. Buzzard JJ, NM Gough, JM Crook and A Colman. (2004). Karyotype of human ES cells during extended culture. Nat Biotechnol 22:381-382.

11. Imreh MP, K Gertow, J Cedervall, C Unger, K Holmberg, $\mathrm{K}$ Szöke, L Csöregh, G Fried, S Dilber, E Blennow and L Ahrlund-Richter. (2006). In vitro culture conditions favouring selection of chromosomal abnormalities in human ES cells. J Cell Biochem 99:508-516.

12. Baker DE, NJ Harrison, E Maltby, K Smith, HD Moore, PJ Shaw, PR Heath, H Holden and PW Andrews. (2007). Adaptation to culture of human embryonic stem cells and oncogenesis in vivo. Nat Biotechnol 25:207-215.

13. Catalina P, R Montes, G Libero, L Sanchez, T de la Cueva, C Bueno, PE Leone and P Menendez. (2008). Human ESCs predisposition to karyotypic instability: is a matter of culture adaptation or differential vulnerability among hESC lines due to inherent properties. Mol Cancer 7:76.

14. Nichols J, EP Evans and AG Smith. (1990). Establishment of germ-line-competent embryonic stem (ES) cells using differentiation inhibiting activity. Development 110:13411348.

15. Liu X, H Wu, J Loring, S Hormuzdi, CM Disteche, P Bornstein and R Jaenisch. (1997). Trisomy eight in ES cells is a common potential problem in gene targeting and interferes with germ line transmission. Dev Dyn 209:85-91.

16. Sugawara A, K Goto, Y Sotomary, T Sofuni and T Ito. (2006). Current status of chromosomal abnormalities in mouse embryonic stem cell lines used in Japan. Com Med 56:31-34.

17. Longo L, A Bygrave, FG Grosveld and PP Pandolfi. (1997). The chromosome make-up of mouse embryonic stem cells is predictive of somatic and germ cell chimaerism. Transgenic Res 6:321-328.

18. Rebuzzini P, T Neri, M Zuccotti, CA Redi and S Garagna. (2008). Chromosome number variation in three mouse embryonic stem cell lines during culture. Cytotechnology 58:17-23.

19. Reynolds BA and S Weiss. (1992). Generation of neurons and astrocytes from isolated cells of the adult mammalian central nervous system. Science 255:1707-1710.

20. Bailey KJ, AY Maslov and SC Pruitt. (2004). Accumulation of mutations and somatic selection in aging neural stem/ progenitor cells. Aging Cell 3:391-397. 
21. Rehen SK, MJ McConnell, D Kaushal, MA Kingsbury, AH Yang and J Chun. (2001). Chromosomal variation in neurons of the developing and adult mammalian nervous system. Proc Natl Acad Sci 98:13361-13366.

22. Rubio D, J Garcia-Castro, MC Martín, R de la Fuente, JC Cigudosa, AC Lloyd and A Bernad. (2005). Spontaneous human adult stem cell transformation. Cancer Res 65:30353039. Erratum in: Cancer Res 65:4969.

23. Miura M, Y Miura, HM Padilla-Nash, AA Molinolo, B Fu, V Patel, BM Seo, W Sonoyama, JJ Zheng, CC Baker, W Chen, T Ried and S Shi. (2006). Accumulated chromosomal instability in murine bone marrow mesenchymal stem cells leads to malignant transformation. Stem Cells 24:1095-1103.

24. Vukicevic V, A Jauch, TC Dinger, L Gebauer, V Hornich, SR Bornstein, M Ehrhart-Bornstein and AM Müller. (2010). Genetic instability and diminished differentiation capacity in long-term cultured mouse neurosphere cells. Mech Ageing Dev 131:124-132.

25. Ferrón S, Mira H, Franco S, M Cano-Jaimez, E Bellmunt, C Ramírez, I Fariñas and MA Blasco. (2004). Telomere shortening and chromosomal instability abrogates proliferation of adult but not embryonic neural stem cells. Development 131:4059-4070.

26. Mi R, Y Luo, J Cai, TL Limke, MS Rao and A Höke. (2005). Immortalized neural stem cells differ from nonimmortalized cortical neurospheres and cerebellar granule cell progenitors. Exp Neurol 194:301-319.

27. Morshead CM, P Benveniste, NN Iscove and D van der Kooy. (2002). Hematopoietic competence is a rare property of neural stem cells that may depend on genetic and epigenetic alterations. Nat Med 8:268-273.

28. Sanai N, A Alvarez-Buylla and MS Berger. (2005). Neural stem cells and the origin of gliomas. N Engl J Med 353:811822.

29. Conti L, SM Pollard, T Gorba, E Reitano, M Toselli, G Biella, Y Sun, S Sanzone, QL Ying, E Cattaneo and A Smith. (2005). Niche-independent symmetrical self-renewal of a mammalian tissue stem cell. PLoS Biol 3:e283.

30. Goffredo D, L Conti, F Di Febo, G Biella, A Tosoni, G Vago, I Biunno, A Moiana, D Bolognini, M Toselli and E Cattaneo. (2008). Setting the conditions for efficient, robust and reproducible generation of functionally active neurons from adult subventricular zone-derived neural stem cells. Cell Death Differ 15:1847-1856.

31. Pollard SM, L Conti, Y Sun, D Goffredo and A Smith. (2006). Adherent neural stem (NS) cells from fetal and adult forebrain. Cereb Cortex 16 Suppl 1:i112-i120.

32. Pollard SM and L Conti. (2007). Investigating radial glia in vitro. Prog Neurobiol 83:53-67.

33. Conti L and E Cattaneo. (2010). Neural stem cell systems: physiological players or in vitro entities? Nat Rev Neurosci 11:176-187.

34. Glaser T, SM Pollard, A Smith and O Brüstle. (2007). Tripotential differentiation of adherently expandable neural stem (NS) cells. PLoS One 2:e298.

35. Spiliotopoulos D, D Goffredo, L Conti, F Di Febo, G Biella, M Toselli and E Cattaneo. (2009). An optimized experimental strategy for efficient conversion of embryonic stem (ES)-derived mouse neural stem (NS) cells into a nearly homogeneous mature neuronal population. Neurobiol Dis 34:320-331.

36. Onorati M, M Binetti, L Conti, S Camnasio, G Calabrese, I Albieri, F Di Febo, M Toselli, G Biella, B Martynoga, F Guillemot, GG Consalez and E Cattaneo. (2010). Preservation of positional identity in fetus-derived neural stem (NS) cells from different mouse central nervous system compartments. Cell Mol Life Sci [Epub ahead of print] DOI: 10.1007/s00018010-0548-7.

37. Louis SA and BA Reynolds. (2005). Generation and differentiation of neurospheres from murine embryonic day 14 central nervous system tissue. Methods Mol Biol 290: 265-280.

38. Okabe M, M Ikawa, K Kominami, T Nakanishi and Y Nishimune. (1997). 'Green mice' as a source of ubiquitous green cells. FEBS Lett 407:313-319.

39. Committee on Standardized Genetic Nomenclature for Mice; MF Lyon, Chair. (1981). Rules for nomenclature of chromosome anomalies. In: Genetic Variants and Strains of the Laboratory Mouse, First Edition, Green MC, ed, Gustav Fisher Verlag, Stuttgart, pp 314-316.

40. Eppig JT, CJ Bult, JA Kadin, JE Richardson, JA Blake, A Anagnostopoulos, RM Baldarelli, M Baya, JS Beal, SM Bello, WJ Boddy, DW Bradt, DL Burkart, NE Butler, J Campbell, MA Cassell, LE Corbani, SL Cousins, DJ Dahmen, H Dene, AD Diehl, HJ Drabkin, KS Frazer, P Frost, LH Glass, CW Goldsmith, PL Grant, M Lennon-Pierce, J Lewis, I Lu, LJ Maltais, M McAndrews-Hill, L McClellan, DB Miers, LA Miller, L Ni, JE Ormsby, D Qi, TB Reddy, DJ Reed, B Richards-Smith, DR Shaw, R Sinclair, CL Smith, P Szauter, MB Walker, DO Walton, LL Washburn, IT Witham and Y Zhu; Mouse Genome Database Group. (2005). The Mouse Genome Database (MGD): from genes to mice-a community resource for mouse biology. Nucleic Acids Res 33(Database issue):D471-D475.

41. Ying QL and AG Smith. (2003). Defined conditions for neural commitment and differentiation. Methods Enzymol 365:327-341.

42. Wang LHC, T Schwarzbraun, MR Speicher and EA Nigg. (2008). Persistence of DNA threads in human anaphase cells suggests late completion of sister chromatid decatenation. Chromosoma 117:123-135.

43. Zatsepina OV, VY Polyakov and YS Chentsov. (1983). Chromonema and chromomere. Chromosoma 88:91-97.

44. Lefort N, AL Perrier, Y Laâbi, C Varela and M Peschanski. (2009). Human embryonic stem cells and genomic instability. Regen Med 4:899-909.

45. Foudah D, S Redaelli, E Donzelli, A Bentivegna, M Miloso, L Dalprà and G Tredici. (2009). Monitoring the genomic stability of in vitro cultured rat bone-marrow-derived mesenchymal stem cells. Chromosome Res 17:1025-1039.

46. Guo J, A Jauch, HG Heidi, B Schoell, D Erz, M Schrank and JWG Janssen. (2005). Multicolor karyotype analyses of mouse embryonic stem cells. In Vitro Cell Dev Biol—Anim 41:278-283.

47. Yang AH, D Kaushal, SK Rehen, K Kriedt, MA Kingsbury, MJ McConnell and J Chun. (2003). Chromosome segregation defects contribute to aneuploidy in normal neural progenitor cells. J Neurosci 23:10454-10462.

48. Yurov YB, I Iourov, SG Vorsanova, T Liehr, AD Kolotii, SI Kutsev, F Pellestor, AK Beresheva, IA Demidova, VS Kravets, VV Monakhov and IV Soloviev. (2007). Aneuploidy and confined chromosomal mosaicism in the developing human brain. PLoS One 2:e558.

49. Kingsbury MA, B Friedman, McConnell MJ, SK Rehen, AH Yang, D Kaushal and J Chun. (2005). Aneuploid neurons are functionally active and integrated into brain circuitry. Proc Natl Acad Sci U S A 102:6143-6147.

50. Kaushal D, JJ Contos, K Treuner, AH Yang, MA Kingsbury, SK Rehen, McConnell MJ, M Okabe, C Barlow and J Chun. 
(2003). Alteration of gene expression by chromosome loss in the postnatal mouse brain. J Neurosci 23:5599-5606.

51. Rehen SK, YC Yung, MP McCreight, D Kaushal, AH Yang, BS Almeida, MA Kingsbury, KM Cabral, MJ McConnell, B Anliker, M Fontanoz and J Chun. (2005). Constitutional aneuploidy in the normal human brain. J Neurosci 25:21762180.

52. Inzunza J, S Sahlén, K Holmberg, AM Strömberg, H Teerijoki, E Blennow, O Hovatta and H Malmgren. (2004). Comparative genomic hybridization and karyotyping of human embryonic stem cells reveals the occurrence of an isodicentric X chromosome after long-term cultivation. Mol Hum Reprod 10:461-466.

53. Leuba SH, TB Wheeler, C Cheng, LeDuc PR, M FernándezSierra and E Quiñones. (2003). Assembly of single chromatin fibers depends on the tension in the DNA molecule: Magnetic tweezers study. Proc Natl Acad Sci U S A 100:495-500.

54. Kepert JF, Fejes Tóth K, M Caudron, N Mücke, J Langowski and K Rippe. (2003). Conformation of Reconstituted Mononucleosomes and Effect of Linker Histone H1 Binding Studied by Scanning Force Microscopy. Biophys J 85:4012-4022.

55. Karymov MA, M Tomschik, SH Leuba, P Caiafa and J Zlatanova. (2001). DNA methylation-dependent chromatin fiber compaction in vivo and in vitro: requirement for linker histone. FASEB J 15:2631-2641.

56. Erenpreisa J and MS Cragg. (2001). Mitotic death: a mechanism of survival? A review. Cancer Cell Int 1:1.

57. Zhang J, X Wang, Z Yanhong, B Chen, G Suo and J Dai. (2006). Neoplastic transformation of human diploid fibroblasts after long-term serum starvation. Cancer Lett 243:101108.

58. Dunbar CE and Larochelle A. (2010). Gene therapy activates EVI1, destabilizes chromosomes. Nat Med 16:163-165.

59. Widenbrant EM and CM Kao. (2007). Introduction of the foreign transposon Tn4560 in Streptomyces coelicolor leads to genetic instability near the native insertion sequence IS1649. J Bacteriol 189:9108-9116.
60. Tenzen T, F Zembowicz and CA Cowan. (2010). Genome modification in human embryonic stem cells. J Cell Physiol 222:278-281.

61. Mothe AJ, I Kulbatski, van Bendegem RL, L Lee, E Kobayashi, A Keating and CH Tator. (2005). Analysis of green fluorescent protein expression in transgenic rats for tracking transplanted neural stem/progenitor cells. J Histochem Cytochem 53:1215-1226.

62. Foroni C, R Galli, B Cipelletti, A Caumo, S Alberti, R Fiocco and A Vescovi. (2007). Resilience to transformation and inherent genetic and functional stability of adult neural stem cells ex vivo. Cancer Res 67:3725-3733.

63. Rakic $S$ and N Zecevic. (2000). Programmed cell death in the developing human telencephalon. Eur J Neurosci 12:27212734.

64. Mantel C, Y Guo, MR Lee, MK Kim, MK Han, H Shibayama, S Fukuda, MC Yoder, LM Pelus, KS Kim and HE Broxmeyer. (2007). Checkpoint-apoptosis uncoupling in human and mouse embryonic stem cells: a source of karyotpic instability. Blood 109:4518-4527.

Address correspondence to: Prof. Elena Cattaneo Department of Pharmacological Sciences and Center for Stem Cell Research

University of Milan

Via Balzaretti 9

Milano 20133

Italy

E-mail: elena.cattaneo@unimi.it

Received for publication August 23, 2010

Accepted after revision January 26, 2011

Prepublished on Liebert Instant Online January 30, 2011 
